\title{
Tenant Satisfaction and Its Evaluation
}

\author{
Olga Vitalievna Lyubova ${ }^{1}$, Oksana Aleksandrovna Aкhmadeeva ${ }^{1}$, Svetlana Yurievna Guzaleva ${ }^{1}$, Svetlana \\ Vitalievna Zubkova ${ }^{1} \&$ Ernst Raisovich Safargaliev ${ }^{1}$ \\ ${ }^{1}$ Naberezhnye Chelny Institute (filial) «Kazan (Volga region) Federal University», Republic of Tatarstan, \\ Russian Federation \\ Correspondence: Olga Vitalievna Lyubova, Naberezhnye Chelny Institute (filial) «Kazan (Volga region) Federal \\ University», 423800, Naberezhnye Chelny Mira Prospekt, 68/19, Republic of Tatarstan, Russian Federation.
}

\author{
Received: October 15, 2014 Accepted: October 29, 2014 Online Published: December 30, 2014 \\ doi:10.5539/ass.v11n3p319 URL: http://dx.doi.org/10.5539/ass.v11n3p319
}

\begin{abstract}
The competitiveness of any enterprise depends on the consumer satisfaction by goods and services produced. Tenant satisfaction with regard to the rented space is a general assessment, which consists of the quality assessment of real estate, service (interaction) quality and quality of service offerings. The article presents the lease options, which are advisable to use when assessing the tenant satisfaction and necessary improvements. The assessment of consumer satisfaction allows one to control the quality management system effectiveness and to identify the areas, in which it is necessary to make improvements.
\end{abstract}

Keywords: consumer satisfaction, quality assessment of real estate, satisfaction rating, main attributes of non-residential premises lease, evaluation of the importance, weighting coefficients

\section{Introduction}

Consumer orientation is a key feature of an effective company management system and one of the basic principles of quality management, developed for use by senior management in order to improve the organization's activities in accordance with ISO 9004:2000.

The ISO 9004-2000 enterprise certification standard, as one of the quality management performance indicators, prescribes a compulsory measure of consumer satisfaction: "Company management should use the measurement of consumer satisfaction as a vital tool" (International Quality Management Systems Standard ISO 9004:2000. Guidelines for performance improvements).

Consumer satisfaction is perception by consumers of the degree, to which their requirements are fulfilled (International Quality Management System Standard ISO 9004: 2000*. Fundamentals and vocabulary).

According to ISO 9000 (International Quality Management System Standard ISO 9004: 2000*. Fundamentals and vocabulary), one should also have in mind that "Even if the consumer requirements have been agreed with the consumer and fulfilled, this does not necessarily ensure consumer's high satisfaction" and "Consumer complaints are a common indicator of low consumer satisfaction, but their lack does not necessarily imply high consumer satisfaction".

Dissatisfaction is the main cause of what is called "the destruction of consumers". In this regard, consumer satisfaction surveys, carried out by Western companies, are the most common in terms of their frequency, especially in the $\mathrm{b} 2 \mathrm{~b}$ markets. It is believed that to retain the existing consumer is several times cheaper than to attract a new one.

In this regard, the so-called "economy of loyal consumers", or the economy, built on consumer retention, has widely spread (Shirochenskaya, 2004). Awareness of the need for such approach led to the development of the programs on building relationships with consumers, called "commitment scheme", which is an action plan to ensure consumers the most favored nation treatment, developed based on accurate and timely information about the needs and desires of consumers. Results of the study identify priorities for improvement, which then are used as a baseline in the quality management system operation (Glushakova, 2001; Glushakova, 2006).

When increasing consumer satisfaction, his loyalty towards the company increases (Kolobova, 2012; Tarelkina, 2006). Thanks to loyal consumers, the company gets free advertising in the form of sincere recommendations that in practice are more effective than various commercials; this results in the influx of new consumers. 
Information about the grievances in terms of quality of products and services disseminates much more intensively than the positive information in case if the client were completely satisfied. Thus, loyal consumers are very profitable. But, according to the experience of the companies, which regularly measure satisfaction, only the higher estimates may be considered acceptable. The high level of consumer satisfaction is based not on the fulfillment of his requests, but on expedience of his needs.

\section{Methodology}

\subsection{Substantiation for the Research on Consumer Satisfaction}

In accordance with the applicable provisions of the ISO 9001:2000 standard (International Quality Management System Standard ISO 9004: 2000. Requirements), the consumer holds a central position in the quality management system, which aims at the constant improvement and increasing consumer satisfaction through the satisfaction of his demands. It is necessary to measure consumer satisfaction that will allow monitoring the quality management system effectiveness and identifying the areas that need for improvements. It is more profitable to retain an existing consumer than to attract a new one. At the same time, the longer the period of retention of the customer, the more profitable he becomes for the company. The best way to retain the consumer is to satisfy his needs. As shown by numerous studies in this area (Lee, 2008; Lifits, 2009; and Moshnov, 2010), highly satisfied consumers are much more likely to become loyal to company than those with low degree of satisfaction. Loyal consumer is a cost effective way to attract new consumers through his recommendations. Consumer needs and expectations may constantly change due to the development of business, the influence of competition and technological development. Therefore organizations have to continuously improve their products and processes. According to some authors (Campanella, 2005; Kotler, 2000; and Faskhiev, 2008), the measurement of consumer satisfaction allows to: determine accurately consumer needs and their priority; comprehend how the consumer perceives the organization; assess whether the organization activities meet consumer demands; determine the ways allowing enhancement consumer satisfaction and establishing priorities for improvement; identify areas of divergence, where the company staff misunderstands consumer priorities or their own capabilities towards consumer satisfaction; set goals for the service improvement and its control in terms of satisfaction indicators. It should be borne in mind that the measurement of consumer satisfaction (MCS) can provide accurate data on the level of consumer satisfaction and identify areas, where the consumer is the least satisfied. Though, without the follow-up activities, MCS cannot insure improvements and enhance the consumer satisfaction.

The ISO standard does not govern the specific procedures for conducting research.

\subsection{Consumer Needs and the Basic Attributes of the Non-residential Premises Lease}

We cannot disagree with a number of authors that consumer satisfaction directly influences the profitability of the business (Faskhiev, 2010; Shaughnessy, 2001).

Tenant satisfaction is determined not only by satisfaction with respect to the quality of provided and used space, but also space location, the possibility of effective exploitation of the territory and infrastructure, as well as quality of deals and interaction (Ahmadeeva \& Lubova, 2011; Efimov \& Samsonov, 2008), i.e. consumer satisfaction in terms of rented premises is a summative assessment, which consists of the quality assessment of real estate, quality of service (interaction) provided, and quality of service offerings. Each of the three groups includes several parameters. Depending on the business specifics, these parameters are adjusted and supplemented. For the identification of these parameters it is necessary to: select parameters based on experience and intuition; conduct the analysis of documents (which are offered to the consumer and which are used by staff, when interacting with consumers, etc.); complete the existing list of specifications by identified parameters; check with the staff of various departments; discuss the ready option with the CEO or Director of Marketing; and carry out a pilot survey of about 10 respondents to check and adjust the list of parameters. When conducting an interview, it is better to put open-ended questions to get the maximum quality information. Afterword it is necessary to structure and generalize a list of parameters without losing the essence and overusing generalized concepts and standard phrases; to improve wording and get approval on the resulted list of parameters from the working party.

Tenant satisfaction depends on the following components:

1. Quality of the space for commercial use:

1.1 Location (transport accessibility, proximity to major roads, and attractiveness of the industrial zone). 
1.2 Characteristics of the area: the quality of the leased premises (industrial, warehouse, and office), the quality of auxiliary premises and public spaces, the building and grounds.

\subsection{Infrastructure:}

- for business (availability of companies providing service and repair of office equipment, availability of financial sector, business services, etc.),

- for employees (the availability of foodservice, health care, hotel, and shops).

2. Quality of service / interaction

\subsection{Service:}

- basic services (property management, maintenance of engineering systems, contractual relations management, etc.),

- additional services (security, parking, access control, cleaning, waste disposal,reception, etc.).

2.2 Interaction with the leasing holder (staff competence and courtesy, easiness to contact the person in charge, settlement of claims, etc.).

3. Quality of the offer (the optimal price-quality relationship, special partner programs, flexible contract terms and pricing policies, etc.).

\subsection{Data Collection Methods and Research Tools}

Data collection methods:

Personal interview. Business consumers are interviewed during the working day on the job at a convenient time. The duration of an interview is on average 10 minutes (but no more than 20 minutes). In case of sufficient number of interviewers and prior agreement with the respondents on behalf of the Company, the interview can be carried out during a period of a few days. Questions should be specifically worded and the questionnaire should be prepared in advance.

1. Telephone interview. Interview through the phone is similar to the personal interview and is carried out during the working hours using a business phone numbers.

2. Survey. Is conducted in writing. Questionnaires can be faxed, e-mailed, mailed, or delivered in person to the office. Collection of filled in questionnaires can be done the same way.

During the study we used mixed methods, including personal interviews, telephone interviews and questionnaires. Questionnaires, which were filled not fully or completed incorrectly, were clarified over the phone.

Basic questionary was compiled:

1) for consumers, renting office space, as well as for those renting production and storage facilities;

2) for consumers, renting only production and storage facilities, while renting office space in another organization.

After the first stage of the survey, the questionnaire was revised and reduced, containing only general estimates, for the purpose of conducting phone survey, as well as for distributing among disloyal-minded consumers.

A special questionnaire was developed to identify the need for additional services and infrastructure. This questionnaire is a basic as well.

Data from the questionnaires, accepted for processing, were presented in a form convenient for further analysis.

\subsection{Investigated Data Population}

The standard does not regulate the process of sampling, but specifies the general requirements and recommendations for measurement, referring to the application of statistical methods. Accurate measurement of consumer satisfaction can be accomplished if it is based on the correct sampling. Many organizations have a large consumer base, especially if operating in the consumer market, and in order to get an accurate assessment of consumer satisfaction there is no need to poll the entire data population. In this case we fall back on sampling.

Steps in developing a sampling plan:

1. Determination of the relevant data population according to the objectives, stated in the study. For b2b-market businesses this includes the formation or obtaining the "list" of data population, i.e. consumers database (the general population). 
2. Study of the general population and its structure.

3. Selection of the coverage of observation units that includes continuous research (the study of the entire general population), or selective research (partial study of the general population).

4. Design of the sampling plan, i.e. the determination of sample composition and size.

4.1 Definition of a sample kind, acceptable for the concerned general population and the research objectives. The samples are divided into two large groups: random (probabilistic) and nonrandom (non probabilistic) samples. In our case, if carrying out a sample survey, the following types of samples are suitable: simple random representational, random systematic, and random stratified (fibered). In order to generalize the conclusion, obtained by studying the sample, to the entire population, the sample should have the property of representativeness.

4.2 Determination of sampling volume (size) in the case of a sample survey. The ISO 9000 standard states that to obtain a reliable sample, when conducting consumer associated measurements, one has to use recognized statistical methods.

To determine the sample size, it is necessary to know the indication sample variance value (Cochran, 1976). It is determined, based on the experience of previous studies or according to the pilot study. If pilot study is laborious and lengthy, the sample size is not pre-determined, while specified in the course of study according to the results obtained. To do this, we calculate span of rating, based on the results obtained; if the representativeness is ensured, the questioning is stopped, otherwise the sample size is specified.

5. Determination of the population access methods.

During the study one verifies the best way to collect data.

Adjustment of methods.

6 Achieving the desired sample size.

7. Verification of sampling for the conformance to the requirements.

8. To form, if necessary, a new sample.

\subsection{Carrying Out Main Study}

The purpose of the main study was to measure consumer perception of the organization.

1) Distribution of questionnaires / checklists. Quantity of questionnaires / checklists should be small enough to carry out the pilot study, after which there probably might be need to adjust questionnaires.

2) Training of interviewers.

3) Pilot study and adjustment of questionnaires.

The main objective of pilot study is to check the suitability of the questionnaire for application, i.e. to identify bottlenecks and problem areas in the questionnaire, to check the questionnaire text in terms of both semantic errors (wording of the questions, the completeness of answers to the questions), and technical errors (correct transitions and links in the questionnaire) (N. Hill, B. Selphie, and G.Roshe, 2004).

1) Data collection (conducting surveys and interviews).

2) Processing of questionnaires.

3) Investigation of consumer complaints.

4) Mirror study. Mirror study is a survey of the company staff and management, using the same set of questions as to the tenant respondents. This survey aims at determination of how well company staff understands what is important to the consumer and how deeply consumers are satisfied.

\section{Results}

\subsection{Data Analysis}

Data processing, preparation and analysis suggest a multiple-table format with a detailed segment-based analysis. The obtained data were processed using the standard Microsoft Excel.

Research can be carried out using digital or verbal scales. In these cases, the data processing and analysis may differ.

Data processing and analysis using questionnaires with digital scales. 
Once a large number of consumers are interviewed to measure the level of their satisfaction and the data are tabulated, it is necessary to carry out some statistical calculations and determine statistical values.

\section{Data processing and analysis using questionnaires with verbal scales.}

If questionnaires contain verbal scales, the results are processed using the frequency distribution, i.e. we determine how many respondents answered the question in a certain way. The results can be presented either as a table or chart, where one scale presents the attributes of the product / service, and the other one shows evaluation of satisfaction or importance. Percentage will determine, for example, how many percent of the respondents are satisfied with respect to a certain parameter. In general, it is an exact summary of the results.

Some researchers believe that the actual problem of verbal scales is the lack of a single average rating for each characteristic. For example, it is impossible to compare the evaluation of the importance of location and the evaluation of tenant satisfaction due to location. Thus, in this case it is impossible to analyze the differences in order to identify priorities for improvement.

\section{Analysis of consumer complaints.}

In addition to the data, obtained during the surveys, it is necessary to analyze consumer complaints. This can be done by composing a list of parameters, peculiar to incoming complaints, and analyzing the frequency of complaints. Any forms of complaints, i.e. written and oral complaints, whether or not collected in a special way, etc., are taken into account. Complaints can be identified in the process of conducting surveys of consumers, who have refused to participate in the basic survey, though expressed their opinions about certain aspects of the company. The results should be presented in tabulated or graphical form. According to ISO 9000 standard, "Consumer complaints are a common indicator of low consumer satisfaction, though their lack does not necessarily imply high consumer satisfaction" (International Quality Management Systems Standard ISO 9004: 2000*. Fundamentals and vocabulary).

\subsection{Progress Report Preparation and Presentation}

Preparation of a progress report using numerical scales.

Importance. Despite the fact that the questions regarding satisfaction precede the questions concerning the importance, the report on assessment of importance should always be the first, as the comprehension of the consumer priorities is a logical starting point (N. Hill, B. Selphie, and G.Roshe, 2004).

If a preliminary pilot study has been conducted, the questionnaire may lack the questions with low importance criterion, though involving the questions with importance of average level and the level above average. Assessment of the importance can be presented in tabular and / or chart forms.

Satisfaction. If the scale is digital, than the average satisfaction scores are displayed for each parameter and the attribute as a whole. Graphically, the order of the parameters corresponds to the level of importance.

Any characteristic with an average rating below average value (for example, six points on a 10-point scale) should be seriously studied and possibly investigated additionally. This will figure out the cause of each low satisfaction score based on conducted research.

For each evaluation of satisfaction, when using digital scales, it is necessary to calculate the standard deviation, because evident satisfactory assessment may hide a group of extremely satisfied consumers, as well as a number of dissatisfied consumers (Hill, Selphie, \& Roshe, 2004).

\section{Satisfaction rating}

The second main result, which is to be obtained from the data collected, is a satisfaction rating. There are several possible ways to determine satisfaction rating:

1) To include into the questionnaire a question about the satisfaction by company operation in general. Difficulty with this approach is that the greater the number of parameters, the more unreliable the answer, whereas this generic question about the consumer satisfaction includes a dozens of parameters.

2) Since the questionnaire already includes the questions on individual parameters, the second approach is to calculate the overall average for all evaluations of satisfaction. This approach is better, though still not perfect, because some factors are more important for consumers than others, and the more important needs have a greater impact on the judgment of consumer satisfaction than less important requirements.

3) Calculation of satisfaction rating should be carried out as a weighted average of satisfaction; this is carried out in two stages: 


\section{Calculation of the weighting coefficients.}

To calculate the weighting coefficients one uses estimates of importance. To calculate the weighting coefficient, all the importance estimates are added up. Then one determines the percentage of the amount received. The data should be presented in tabular form.

Each satisfaction score (average) is multiplied by its corresponding weighting coefficient.

Complete weighted average is obtained by adding all the weighted estimates and is expressed as a percentage. Satisfaction rating indicates that the organization satisfies consumers at a certain percentage. Maximum satisfaction rating equals to $100 \%$.

Preparation of a progress report using verbal scales.

The report begins with an analysis of importance.

When processing verbal scales, one mainly uses frequency distribution. To simplify the report, one may use satisfaction percentage. For the normal five point verbal scale, this is a sum of the numbers in the first two cells ("highly satisfied" and "satisfied"), representing the sum of the number of respondents, who gave the corresponding assessments.

The disadvantage of this approach is that three of the five data arrays collected is ignored. For example, satisfaction may look acceptable in terms of certain parameters, though within this point may take place the highest percentage of very dissatisfied consumers. The combination ratings in the first two cells are ignored as well. That is, the use of these estimates alone can give a slightly different result than their sum. Where consumers are generally satisfied (as is the case for most organizations), most of them put a tick in the second cell ("satisfied"). But unfortunately, as shown by research in this area, the relationship between consumer satisfaction and his loyalty is often exponential. In other words, the relationship between satisfaction and loyalty is much stronger for those, who indicated "highly satisfied", than for those consumers (much more numerous), who are simply "satisfied". That is, reliable in terms of loyalty are only those consumers, who are very much satisfied; thus when drawing conclusions it is necessary to focus attention exactly on this group of respondents.

Layout of progress report is carried out in a word format with lots of graphics. One can use also the Power Point presentation program.

Structure of the report is generated at the discretion of the person, drawing the report, though taking into account the above noted recommendations.

\section{Discussion}

The aim of this study was to measure the perception of the leasing holder organization by the tenants. The assessment of the satisfaction with industrial, warehouse and office premises was based on selected lease options.

The study was conducted with the use of digital and verbal scales. As a result, it was revealed that the order, in which the questions were listed in the questionnaire, is not suitable for the report. It was necessary to determine the order of priorities and list the parameters in accordance with their importance to the consumer throughout the progress report.

Information can be clearly represented using satisfaction diagrams, though the most useful results can be obtained, when bringing together the assessments of the importance and satisfaction, identifying further the company performance quality in the areas, most important for the consumer.

The most important are the indicators for which the company was unable to meet the demands of consumers. These are exactly the indicators, which need careful attention to improve consumer satisfaction, so called PFI areas (priorities for improvement). The greater the gap, the greater the problem. The largest PFI, i.e. factor with the greatest potential to improve consumer satisfaction, is associated not with a query that received a minimum score of satisfaction (a quick cashier services), but a query, which has a maximum gap in the estimates of importance and satisfaction.

It is important that the satisfaction rating is updated in the process of monitoring. This gives a measure of satisfaction, which can be controlled in future periods, even if the questions in the questionnaire will need to change due to changes in consumer demand. Basically satisfaction rating gives an answer to the following question: "How well we satisfy our consumers with respect to $m$ variables that are the most important to them?" 
If in the future the questionnaire will need to change as a result of changes in consumer priorities, then the satisfaction rating will still remain adequate measure, suitable for comparison. This comparability is applicable to consumer segments as well.

Because of the statistical impossibility of obtaining the average scores from categorical or ordinal scales, there is no satisfactory method of obtaining a weighted average of estimates for the calculation of satisfaction rating. Using a verbal scale in reports, one usually averages satisfaction scores for all inquiries, or presents as satisfaction rating the result, obtained with respect to overall satisfaction.

Variance analysis is also problematic. When using the approach, associated with the first two cells, it is possible to compare estimates of the importance and satisfaction, though the lack of $60 \%$ of the scale makes this method too rough. Therefore, when using a verbal scale, it is considered the best to determine PFI based only on estimates of satisfaction. But in the case of verbal scales, one can use the presentation of priorities for improvements using other techniques, such as matrices, profiles, etc.

\section{Conclusion}

Since the introductory clause of the ISO 9001:2000 standard states that the organizations should focus on "continuous improvement of process, based on objective measurement", it is necessary to conduct a formal investigation of consumer opinions.

Standard 9001:2000 leaves the responsibility for "determination of applicable methods, including statistical techniques", when conducting measurements of consumer satisfaction, to the organization. Application of both digital and verbal scales is allowed.

The numerical scales are processed using mean values and standard deviations, while the verbal scales require using frequency distributions. Numerical scales are more suitable for statistical analysis, expanding the scope of its application. Verbal scales are more convenient and intuitive to respondents with respect to satisfaction ratings. It is considered incorrect to convert verbal responses into numerical scales at the stage of processing the results. Conclusions with respect to satisfaction ratings will be vivid in both cases.

Identifying gaps between importance and satisfaction, one reveals the priorities for improvement. In the case of verbal scales, one can use the presentation of priorities for improvements with the help of matrices, profiles and other methods, including those developed by the researcher.

It is advisable to derive the general satisfaction rating, which must be a weighted average rating. This general satisfaction rating can be further used for comparative analysis in the monitoring.

Actions taken to improve the satisfaction, based on results of the study, will be mainly focused in the designated areas of low satisfaction and increased importance. The actions content lie within the competence of the company, rather than research.

\section{References}

Ahmadeeva, O. A., \& Lubova, O. V. (2011). Rental market of production and warehousing of Naberezhnye Chelny. Socio-Economic and Technical Systems, 3(60). Retrieved August 20, 2014, from http://www.sets.ru

Campanella, J. (2005). Economics of quality. Basic principles and their application. M.: Standards and Quality.

Cochran, W. (1976). Sampling methods. M., Statistics.

Efimov, V. V., \& Samsonov, M. V. (2008). Basics of quality assurance: A tutorial. Ulyanovsk: Ulyanovsk State Technical University.

Faskhiev, H. A. (2008). How many parameters are needed for a reliable assessment of the goods quality? Marketing in Russia and Abroad, 1.

Faskhiev, H. A. (2010). Consumer satisfaction and its evaluation. Marketing in Russia and Abroad, 2.

Glushakova, T. (n. d). Measurement of consumer satisfaction and business management. Retrieved August 20, 2014, from http://www.ateh.ru/conten/

Glushakova, T. (n. d.). Satisfaction controls the quality. Retrieved from http://www.advlab.ru/articles/article 157.htm

Hill, N., Selphie, B., \& Roshe, G. (2004). Measurement of consumer satisfaction according to the ISO 9000 standard. M.: Publishing House "Tekhnologiya".

International Quality Management Systems Standard ISO 9001:2000. Requirements. 
International Quality Management Systems Standard ISO 9004: 2000*. Fundamentals and vocabulary.

International Quality Management Systems Standard ISO 9004:2000. Guidelines for performance improvements.

Kolobova, E. P. (2012). The formation and assessment of the consumer loyalty level. Problems of the Contemporary Economy, 2(42).

Kotler, F. (2000). Marketing in the third millennium: how to create, win and retain market. M.: ACT.

Lee, G. (n. d.). Consumer satisfaction and loyalty. Retrieved August 25, 2014, from http://www.bma.ru/biblioteka-marketologa/udovletvorennost-potrebitelej-i-loyalnost/?lang=ru

Lifits, I. M. (2009). Competitiveness of goods and services. Textbook. M.: Higher Education.

Moshnov, V. A. (n. d.). Comprehensive assessment of the enterprise competitiveness. Retrieved August 25, 2014, from http://www.cfin.ru/management/strategy/

Shirochenskaya, I. P. (2004). Basic concepts and methods of loyalty measurement. Marketing in Russia and Abroad, 2.

Shonessy, J. O. (2001). Competitive Marketing. Strategic Approach. St. Petersburg: Peter.

Tarelkina, T. V. (2006). Monitoring of consumer satisfaction. Sales Management, 11.

\section{Copyrights}

Copyright for this article is retained by the author(s), with first publication rights granted to the journal.

This is an open-access article distributed under the terms and conditions of the Creative Commons Attribution license (http://creativecommons.org/licenses/by/3.0/). 